\title{
Claves de los weblogs \\ y su influencia en la prensa tradicional
}

\section{Jesús Miguel Flores \\ y Guadalupe Aguado}

Profesores de la Universidad Antonio de Nebrija

\section{Resumen:}

En el presente artículo se profundiza en el concepto de los weblogs y todo lo que este fenómeno implica. Se analizan los factores que han incidido en su proliferación y difusión, determinantes en su consolidación, partiendo desde su facilidad de creación, características y tendencias de uso. Además, dicha reflexión tiene por objeto efectuar un análisis sobre la influencia de los weblogs en el periodismo y los medios, hasta qué punto se puede hablar de ellos como estrategias de negocios, su uso como fuentes de información -y los consecuentes debates sobre su fiabilidad- y la expansión del llamado periodismo participativo.

Palabras clave:

Periodismo, blog, bitácora, comunicación, medios, información, negocios.

\section{Abstract:}

In the present article one deepens in the concept of weblogs and everything what this phenomenon implies. The factors are analyzed that have affected their proliferation and diffusion, determinants in their consolidation, starting from their facility of creation, characteristics and tendencies of use. In addition, this reflection intends to carry out an analysis on the influence of weblogs in the media and journalism, to what extent it is possible to be spoken of them like strategies of business, their use as debate and sources of intelligence-consequent on its reliability-and expansion of the called participative journalism.

Key words:

Journalism, blog, communication, mass media, information, business. 


\section{Introducción}

Los weblogs, también conocidos como blogs o bitácoras (ésta última, en un intento de acercar el significado en español) suscitan controversias entre los diferentes sectores, incluso a la hora de definirlos. En 1999, el diario norteamericano The Chicago Tribune ofreció una de las primeras definiciones de lo que es un weblog: "Un sitio que contiene una serie de links constantemente actualizada; estos links pueden tratar de diferentes asuntos o focalizarse en uno particular"'.

José Cervera ${ }^{2}$, periodista free lance del diario 20 minutos, y administrador del blog Perogrullo indica que, "el weblog es el hijo no reconocido de la columna de opinión y la revista de prensa; a veces es más columna y a veces más revista, pero idealmente tiene un poco de los dos”.

Para otros, un weblog es un sitio de encuentro o foro de expertos en los temas más variados, donde se intercambia información de primera mano. Los participantes del foro elaboran artículos que publican en el web como si se tratara de un tablón de anuncios ${ }^{3}$.

El debate se plantea igualmente entre los que consideran a los blogs como diarios personales y los que ven en los mismos el resultado de múltiples colaboraciones ${ }^{4}$.

Pero más allá de la falta de entendimiento en las definiciones podemos extraer ciertos rasgos comunes a los múltiples weblogs. En este sentido percibimos que un weblog es una página web personal, temática o no, que puede contener textos, imágenes y links, en la que se anotan como si de un diario se tratara cuantas referencias se estimen oportunas. En unas ocasiones, el blog es elaborado por una sola persona y en otras, por una comunidad que comparte inquietudes y gustos. Pero tanto en unos como en otros a efectos de estructura de contenidos, mensajes o posts impera la organización cronológica por encima de otras. Contienen textos propios y ajenos, curiosidades, intimidades y links a otros weblogs. Es una nueva forma de comunicación que en muchos casos pone en cuestión criterios periodísticos como la objetividad, la pirámide invertida o la clasificación por géneros, al tiempo que da cabida a hábitos como la interrelación informativa y la interactividad con el receptor de la información ${ }^{5}$.

El creador de una bitácora o blog que mantiene una constancia periódica de uso, pasa a denominarse en el argot de la Red, blogger o bloggero. El acto de mantener el sitio blog con la inclusión de contenidos, se define como blogging, y el tratar el mundo blog se denomina blogosfera.

1 “Reflexiones sobre el mundo del weblog": www.paraperiodistas.com, 15 de septiembre de 2004.

2 Manchón, Eduardo: “Entrevista a José Cervera: Weblogs e Internet en España”, alzada@org, 3 de septiembre de 2004.

${ }^{3}$ Olivares, Paco: “iLos nuevos media implican una nueva ética?”, espanol-geocities.com

4 "Entre estos nuevos medios o formas de hacer periodismo, dejando a un lado las versiones digitales de los medios tradicionales, podemos distinguir dos tipos: Los medios unipersonales y los que son el resultado de las aportaciones de un colectivo, también conocidos como weblogs”. Olivares, Paco: “¿Los nuevos media implican una nueva ética?”, espanol-geocities.com.

${ }^{5}$ En algunos casos como elsemanaldigital.com, calificado por sí mismo como el primer weblog de la prensa española, estas pautas no se cumplen, por lo que es difícil establecer la diferencia entre un weblog y una publicación electrónica de otra naturaleza. 


\section{Análisis de los rasgos de identificación de los blogs}

Las herramientas y recursos de información que existen en la Red deben ser utilizadas de una forma óptima por los profesionales de la información (Flores y Arruti, 2001: 134). Así pues, en un intento de comprender mejor las características de esta nueva herramienta de comunicación, sobre todo, como potencial recurso de información, extraemos los siguientes rasgos de identificación, puestos de manifiesto por expertos profesionales de la creación de bitácoras:

\subsection{Facilidad de creación y mantenimiento}

El software de edición de weblogs (como UserLand, Moveable Type o Greymatter, basados todos en $\mathrm{XML}$ ) ha sido simplificado y democratizado. Existen ya numerosas plataformas digitales (Blogger, Weblogger, LiveJournal, etc., y en España, Blogia, La Coctelera, Ya.com, Barrapunto, etc.) que permiten a los particulares crear con facilidad sus weblogs (con plantillas predeterminadas, espacio de servidor gratuito, tutoriales, etc.).

\subsection{Simplicidad en la interface de edición}

Se introduce el texto en la ventana de texto, se aprieta el botón "editar" y listo, el texto queda editado en Internet. El weblogger o blogger del weblog puede concentrarse en la búsqueda de información o en la escritura. La rapidez con la que el weblog puede ofrecer la información hace de él una herramienta insustituible para situaciones urgentes. Dan Gillmor, veterano periodista, convertido en célebre animador del blog de SiliconValley.com, la vitrina tecnológica del periódico californiano San José Mercury News, tiene su propia versión del mundo blog .

\subsection{Constante y regular actualización}

"Es un trabajo enorme, es como una bestia insaciable que tiene hambre continuamente", sostiene Dan Gillmor. La madurez y longevidad de un weblog están relacionadas con la resistencia de su creador.

\subsection{El hipertexto como elemento imprescindible}

Es una de las grandes fuerzas de los weblogs al permitir la recuperación de informaciones que ya no son del todo actuales pero siguen siendo relevantes. Estas informaciones son a veces de primera mano (creadas y editadas por el blogger, como los numerosos y contundentes testimonios aparecidos en los

\footnotetext{
${ }^{6}$ Dan Gillmor cuenta la anécdota de un terremoto producido en Seattle a las 10.55 de la mañana, que se incluyó a las 10.59 en un artículo breve en el weblog colectivo Metafilter, seguido de varios comentarios irónicos sobre la lentitud de la CNN o de Yahoo! a las 11.06, o sea, más de un cuarto de hora antes de las primeras reacciones de los medios aludidos.
} 
weblogs neoyorquinos en las horas siguientes a los atentados del 11 de septiembre en EE.UU.). Pero, en la mayoría de los casos, se trata de información reciclada, sacada de las profundidades de la Red, que proviene de otras páginas web o de otros weblogs. "Los weblogs hacen las veces de filtro", señala Dan Gillmor. "En la masa de información disponible en la Red, los bloggers tratan de encontrar los elementos más interesantes. Abren el camino a los demás internautas”.

\subsection{Consideradas buenas herramientas de referencia}

Citemos, por ejemplo, Blogdex (blogdex.media.mit.edu), que es el proyecto de un estudiante del MIT, (Massachusetts Institute of Technology), que recoge las direcciones URL más consultadas por los weblogers; blogs docentes, como el caso de Paraninfo de la Facultad de Ciencias de la Información de la UCM (http://paraninfo.blogspot.com) o el blog Bookwatch (www.onfocus.com/bookwatch), que recopila las páginas de Amazon seleccionadas por los weblogers y construye una lista, actualizada continuamente, de sus libros favoritos: un complemento ideal a las tradicionales listas de best-sellers que clasifican las obras según las cifras de venta.

\subsection{Interacción y participación en comunidades}

Los bloggers constituyen comunidades muy vivas y muy unidas. Introducen en sus páginas web vínculos hacia páginas web semejantes, de otros weblogers con los que comparten descubrimientos y afinidades. Esta interconexión crea un poderoso efecto multiplicador: "Una comunidad de diez, cien o mil personas que intercambian ideas y comentarios pueden crear un dinamismo increíble”, comenta Henry Copeland, director general de Pressflex, proveedor de soluciones completas para la prensa. "Es una gran satisfacción, intelectual y comercial, porque siempre se pueden encontrar personas con los mismos intereses profesionales".

\section{Factores clave en la proliferación y difusión de los weblogs}

Atendiendo a la definición de weblog como una particular forma de ver la web a través de enlaces, existe la creencia de que el primer blog lo creó el que fuera también uno de los padres de la red Internet, Tim Berners-Lee, ya que se dedicaba a indicar los nuevos sitios que se creaban a medida que se iban colgando en la Red.

Después, el número de blogs ha ido creciendo desmesuradamente, desde aquellas listas que proporcionaban las páginas "What's New" de la NCSA (National Center Science Agency) y Netscape, tanto que se preveía que alcanzase la cifra de 10 millones a finales del 2004.

La gente empezó a escribir blogs, sobre todo porque sistemas como Blogger eran un método sencillo de publicar en la Red. Como tantas otras veces en la historia, las limitaciones tecnológicas provocaron 
el nacimiento de un formato distintivo con una personalidad única. El éxito radica en que por primera vez el usuario es editor, crítico, periodista, escritor y de una forma sencilla sin conocer la utilización de HTML.

Los desarrolladores de software han visto el filón de audiencia que tiene este género en Internet y ya no es necesario ni dominar el HTML (Hyper Text Markup Language o Lenguaje de Marcas de Hipertexto) ni conocer el manejo de los programas FTP (File Transfer Protocolo o Protocolo de Transferencia de Ficheros) para poder contar con un diario Online. EditThisPage y Pitas son algunos de los sitios que ofrecen herramientas gratuitas para actualizar weblogs, aunque la que más furor ha causado es Blogger ${ }^{7}$, un servicio nacido en 1999 que permite crear diarios llamativos y de manera muy fácil, y que ya tiene más de 2,5 millones de usuarios activos en todo el mundo.

A su divulgación también contribuye el que hasta ahora los weblogs han tenido muy buen posicionamiento en Google y otros buscadores, lo que provoca que muchas búsquedas den como resultado páginas de weblogs. Además, las tecnologías utilizadas por las bitácoras permiten indexarlos muy bien y la enorme cantidad de vínculos entre weblogs los potencian en los rankings de resultados.

El perfil de muchos autores, personas conectadas permanentemente a la Red y ligados a su desarrollo, provoca que tengan muchas visitas y un gran peso específico. Recientemente, el buscador Google, en un movimiento de ficha estratégica en el mundo blog, ha desarrollado un buscador Google, únicamente para blogs, en versión beta.

La gratuidad es un concepto latente en Internet, que frena, en cierta forma, el desarrollo de las empresas que buscan implantar un modelo de negocio basado en las nuevas herramientas de comunicación (Flores y Aguado, 2005: 78). Este mismo concepto, el de la gratuidad, permite alentar al internauta a confeccionar este modelo de ciberdiario. La mayoría de herramientas creadas para este fin son gratuitas, aunque existen algunos sistemas de publicación como "Manila" o "Move Type" que son de pago. Los tres elementos principales que computan en la no gratuidad son: la propia herramienta seleccionada para crearlos, el espacio dedicado para hospedar las páginas y el nombre asociado al mismo.

Evidentemente, la clave en el desarrollo de los blogs ha sido el sentimiento de comunidad y apoyo mutuo. Pero con recomendar weblogs hay que tener cuidado, pues a los lectores no les es de utilidad que un weblog vincule sin razón a otros con el único objetivo de obtener reciprocidad. Vincular supone avalar una página, recomendarla a los lectores porque se considera interesante o de utilidad.

Por otro lado, muy pocos autores se molestan en escribir una pequeña explicación sobre los vínculos que recomiendan para que el lector pueda valorar si le puede interesar visitarlos o no. El nombre de la bitácora vinculada suele ser la única indicación.

${ }^{7}$ Existe una gran facilidad para crear blogs propios a través de herramientas como "Blogger", "Pitas”, "GreyMatter", "Moveabletype" y, en español, "Bitácoras.net". 
Ante la influencia de dichos factores no ha de perderse de vista que, a largo plazo, más allá de los condicionantes técnicos o económicos el éxito de los weblogs se asentará en la credibilidad que merezcan a la audiencia y a todos aquellos que los toman como referente informativo o de estados de opinión.

\section{El negocio que se mueve alrededor de los weblogs}

De acuerdo con el catedrático de periodismo Timoteo Álvarez (Timoteo Álvarez, 2005: 94) se considera prudente no entrar de lleno en todo el fenómeno de los contenidos "ontime", "online" y "onmovil" de la oferta de datos e informaciones al minuto por pantalla de teléfonos, etc., porque son aún situaciones inciertas y dadas las experiencias recientes, no conviene magnificar. Sin embargo, en Estados Unidos, donde cientos de blogs cuentan con miles de lectores habituales, el fenómeno es verdaderamente explosivo, lo que ha obligado al "zar de la comunicación", Rupert Murdoch, a reconocer recientemente que los medios habían sido incapaces de prever la influencia que Internet "y notablemente los blogs" habrían de tener sobre la juventud actual. Murdoch dijo esto durante el desarrollo de su conferencia dada en abril de 2005, ante un auditorio repleto de editores y periodistas de la American Society of Newspaper Editors. Allí, sugirió también que los diarios experimenten con los bloggers y el periodismo ciudadano.

En el sitio web de la American Society of Newspaper Editors titulan la crónica sobre su conferencia con una frase textual: "Soy un inmigrante digital". Es una frase resignada, de aceptación. Rupert Murdoch indica que la pelea que él y los editores de medios impresos tienen que librar es en el "extranjero digital". Deben aprender el idioma de "ese país" y hacerlo rápidamente.

Durante el desarrollo de la conferencia, Murdoch comentó otras cosas muy importantes. Entre las cuales se destaca, en primer término, su advertencia sobre la tendencia de los jóvenes de abandonar la lectura de diarios, que cree es indeclinable. Para ello citó un estudio de Carnegie Corporation que afirma que el $44 \%$ de los usuarios entre 18 y 34 años consultan la web al menos una vez al día y que apenas el 19\% leen un diario. En función de ello, dijo a los editores presentes: "Estoy seguro de que todos sus diarios tienen una versión web, pero ¿cuántos se toman en serio la relación con esos lectores y los negocios de Internet?", instándoles también a invertir, investigar y experimentar sobre el modelo de comunicación que se expande cada vez más. Ha hecho hincapié en los redactores y editores que no tienen contacto con los lectores, sobre todo con los nativos digitales".

Murdoch, como sabemos, es el magnate número uno de los medios de comunicación del mundo. Es dueño de decenas de diarios, productoras y distribuidoras cinematográficas, de Direct TV, de Los Ángeles Laker, etc. Recientemente, su grupo, News Corp., ha invertido cerca de 1.300 millones de dólares -unos 1.080 millones de euros- en la compra de sitios que van desde MySpace.com -orientado al público adolescente- al portal de videojuegos GameSpy.com. Está claro que su estrategia en el mundo de los negocios de comunicación pasa por posicionarse en el mundo digital tal como lo ha hecho en el entorno tradicional de los medios. 
Y es que cuando Murdoch dice algo, hay que prestarle mucha atención. No importa que lo dicho sea una idea conocida, ni siquiera que suene vieja para muchos. Es en ese momento cuando se vuelve real.

Desde otra perspectiva, vemos que alrededor de los blogs han surgido nuevas herramientas, como es el caso de Geoblog, una página que muestra en tiempo real las actualizaciones de multitud de weblogs, y de Que buscas QUE?!, un sitio web que recoge los registros por los cuales los internautas llegan hasta páginas personales, que nada tienen que ver, en muchas ocasiones, con lo que están buscando ${ }^{8}$.

Geoblog recoge los cambios de las bitácoras que previamente se han registrado. Los cambios en tiempo real de los blogs se representan en un mapa mundi con un punto rojo sobre el país de origen de la bitácora. Cada punto rojo enlaza a la bitácora que se actualiza en ese momento. Geoblog es un diario personal en inglés que se mantiene y crece gracias a la colaboración de otros autores de blogs. Para que una página personal se represente en el mapa mundi cada vez que se actualice el responsable debe de registrase e incluir un código en su weblog. Hasta el mes de mayo de 2004 estaban registradas un 13 por ciento de las bitácoras del mundo.

El interés que han despertado los weblogs ha llegado a influir en las estrategias de Google Corp., que después de arrasar en el mundo de los buscadores, los grupos de noticias y la información de última hora, se ha fijado en un nuevo objetivo: los weblogs. Con la adquisición de Pyra Labs, compañía de San Francisco que ha desarrollado Blogger (el mayor sistema de creación de weblogs, con 2,5 millones de usuarios repartidos por todo el mundo), la marca más conocida del mundo se hace con más de dos millones de bloggers de un plumazo. Google no sólo pretende hacerse con los usuarios activos de Blogger, que son miles, sino también conseguir un hueco en el emergente mercado que suponen los creadores de diarios online ${ }^{9}$. De ahí la estrategia, comentada en párrafos anteriores, de crear un buscador de blogs.

En mayo de 2004 el buscador más utilizado por los internautas de todo el mundo desarrolló su propia weblog. La finalidad de esta nueva página es la comunicación con los usuarios y especialmente la función de relaciones públicas del propio buscador. En el weblog oficial los empleados de Google informarán a diario sobre tecnología, temas de actualidad y el mundo de las búsquedas.

La finalidad de este weblog es la comunicación con los internautas y la función de relaciones públicas del propio buscador. En él, los empleados irán introduciendo noticias sobre Google y las reflexiones de sus socios y dirigentes sobre la actualidad del sector desde un enfoque tanto técnico como empresarial. El blog no permite una interacción directa, a cambio ofrece a los lectores la posibilidad de enviar sus impresiones sobre la página a través de la siguiente dirección de correo electrónico,

\footnotetext{
${ }^{8}$ Guilarte, Natalia: “Nuevas formas de buscar 'weblogs' en todo el mundo”: elmundo.es, 29 de agosto de 2003.

${ }^{9}$ Cernuda, Olalla: “Google compra más de un millón de diarios personales”: elmundo.es, 17 de febrero de 2003.
} 
gblog@google.com. En realidad se trata de una iniciativa que pretende acercar la imagen de esta gran corporación a sus usuarios a través de presentar un rostro más humano y cercano, el de la gente que trabaja en ellas.

Son las reglas de juego de las estrategias digitales; sin ir más lejos, la propia empresa Microsoft ya cuenta con una iniciativa similar con Channel 9. En esta línea de negocio, Microsoft, el mayor fabricante de software del mundo, anunció el lanzamiento de un servicio de diarios on line o weblogs en Japón a modo de prueba, y aspira a tener un millón de usuarios en el primer año ${ }^{10}$. En mayo, el presidente de Microsoft, Bill Gates, dijo que los weblogs y la forma en que son distribuidos pueden utilizarse como herramientas de comunicación de actividades. Además, señaló la creciente percepción por parte de Microsoft del blogging como una potencial amenaza, pero también como una nueva oportunidad de negocio.

\section{Los weblogs frente a los medios tradicionales de información}

Internet es el tejido de nuestras vidas (Castells, 2001: 15) y cada día es más frecuente el desarrollo periodístico a través de blogs realizados por profesionales, generalmente de los llamados free lance, para dar a conocer sus puntos de vista al margen de lo que publican en los medios tradicionales en los que colaboran. Internet es un magnífico lugar para que no tengan mayor limitación que la de su propia capacidad para contar los hechos de los que son testigos. Son, por tanto, un vehículo de comunicación que, como cualquier otro medio de comunicación, pueden ir creando un archivo propio de las noticias, imágenes o infografías que se publican en la Red.

El blogging, hobby de informático convertido en fenómeno de masas ${ }^{11}$, ha suscitado algunas inquietudes, como en su tiempo Internet: ¿Se trata de verdad de un nuevo medio de información?, ¿representa una amenaza para los medios de información tradicionales? Algunos de los weblogers pioneros, especialmente Dave Winer (www.scripting.com), disfrutan con la provocación, presentándose como los "Robin de los bosques" de la información alternativa y democrática, que se oponen al poder superior de los medios tradicionales concentrados y embrutecedores.

A la provocación responden ciertos periodistas "tradicionales" de modo estéril, tachando a los weblogers de "reporteros frustrados en crisis creativa". Otros, sin embargo, han aceptado con entusiasmo lo que han venido a considerar como una nueva y preciada herramienta de comunicación e información. "Plumas" del Newsweek, del The New York Times o de grandes e-zines (Salon.com, Slate.com...) como Andrew Sullivan, Virginia Postrel o Mickey Kaus han sabido apreciar inmediatamente la amplia oferta

\footnotetext{
10 “Microsoft lanza un servicio de weblogs en Japón”: elmundo.es, 4 de agosto de 2004.

${ }^{11}$ Tres millones y medio de weblogs se han registrados en el mundo, de los cuales la mayoría se encuentra en Estados Unidos, con más de 2.000 creaciones diarias.
} 
de matices de los weblogs, la ausencia de censura y de limitaciones de formato. Menos numerosos han sido los que, más allá de su placer individual, insisten en que los grandes grupos multimedia incorporen weblogs en su estrategia digital para enriquecer el "menú". Dan Gillmor y JD Lasica (Online Journalism Review) se cuentan entre éstos, y no les faltan argumentos que dan fe de la utilidad de los blogs para los medios digitales. En opinión de Gillmor ${ }^{12}$, los periodistas que han comenzado a utilizar esta herramienta, los weblogs, bien sostenidos por su especialización y por los numerosos vínculos a los que remiten, constituyen, para empezar, una importante fuente de información complementaria para las redacciones tradicionales, que cada vez están más limitadas en cuanto a los medios y, sobre todo, en cuanto al tiempo. Los bloggers harían así realidad los vaticinios de algunos visionarios de la web, que prometían la venida de un nuevo tipo de periodistas ocupados en desentrañar los secretos del mundo virtual en lugar de batirse en duelo con el mundo real. No obstante, Gillmor indica que, "nadie sugiere que las consultas a los weblogs puedan reemplazar las virtudes del periodismo tradicional: la investigación, el reportaje sobre el terreno, la escrupulosa comprobación de los datos y las fuentes. Los dos argumentos no son incompatibles, sino complementarios".

La credibilidad es un factor importante que intentan posicionar los weblogs, teniendo presente que el hecho de poder publicar en Internet y tener un cierto anonimato no implica que se pueda mentir o difamar. Precisamente en relación con este aspecto se ha manifestado una preocupación acerca de la libertad-impunidad para escribir en ellos, teniendo en cuenta que son un escaparate al público y que nadie se hace responsable de su contenido, ya que incluso el autor puede evadirse con pseudónimos. Pero éste es un problema de fondo que entraña la propia concepción de la Red, la ausencia de normativas y de legislación que delimite determinados tipos de contenidos en los que la información puede resultar, además de falsa, hiriente e injuriosa para individuos en concreto. Encontrar una solución a este respecto en relación con los weblogs pasaría de forma concreta por la aplicación de una regulación de contenidos a todo lo que Internet abarca ${ }^{13}$.

Precisamente, la prioridad en la inmediatez sobre el contraste de las fuentes es lo que ha llevado a triunfar a algunos blogs, como es el caso de la publicación que elabora Matt Drudge, The Drudge Report, que salió a la luz por publicar un rumor que hacía semanas que iba de redacción en redacción: el presidente Clinton podía estar manteniendo relaciones sexuales con una becaria de La Casa Blanca. La noticia no había sido confirmada y no había prácticamente ninguna prueba, sin embargo Drudge no tuvo ningún reparo en publicar la información, incluyendo además el nombre de la becaria, Monica Lewinsky. El caso Lewinsky fue hecho público en la página de Drudge el 17 de enero de 1998, cuatro

\footnotetext{
${ }^{12}$ En opinión de Gillmor, "del mismo modo que las revistas y las cadenas de televisión toman una gran parte de sus contenidos de los periódicos, estos últimos rastrean toda la Red en busca de noticias confidenciales o rumores por confirmar. La prensa ha tenido siempre vocación de cámara de resonancia, pero Internet ha aumentado el volumen y ha acelerado el ritmo".

13 “Reflexiones sobre el mundo del weblog": www.paraperiodistas.com, 15 de septiembre de 2004.
} 
días antes de que apareciera en el Washington Post o en la cadena televisiva $A B C$. El 21 de enero, Matt Drudge era entrevistado en las principales cadenas de televisión de Estados Unidos. Su mérito era haber sido el primero en publicar una información sin contrastar. The Drudge Report comenzó a publicarse en 1995 y sirve una media de un millón de páginas al día.

En España, precisamente la circulación de rumores y el peligro que ello conlleva ya se ha dejado notar en algunos casos como la sentencia publicada sobre el "caso Hesperia" en la que se ha condenado a Micanoa.com (ahora llamado DiarioDirecto.com) a pagar 600.000 euros a cinco jugadores del Barcelona por intromisión ilegítima en los derechos al honor y a la intimidad ${ }^{14}$. Esta sentencia es un aviso a los navegantes que han de cuidarse de publicar según qué cosas.

Sin embargo, los medios digitales no son ajenos a efectuar un trabajo de selección, aunque lo hacen más bien de modo puntual, en algunas páginas o secciones concretas, o con motivo de ocasiones especiales (informes, eventos...). Son raros los medios que lo hacen de modo sistemático, reestructurando estos vínculos en una sección aparte que tendría justamente la forma de una bitácora. Sin embargo, desde 2000 el sitio de The Guardián ${ }^{15}$ hace exactamente esto, lo que acarrea 60 millones de páginas vistas al mes.

Dan Gillmor cree también que el blog está llamado a generar más interacción ${ }^{16}$. Para el colaborador del San José Mercury News, se trata de construir un nuevo contrato de lectura, menos jerarquizado, menos formal. "Estamos pasando de un discurso doctrinal y unilateral a un fenómeno situado entre la conversación y el seminario”.

\section{Convertir el blog en una herramienta del periodismo}

El fenómeno blog es tal que, recientemente, el sitio web de la prestigiosa revista estadounidense Business Week viene ofreciendo la realización del un curso superior, MBA Blog, que lógicamente está enfocado a los profesionales de la información. Algunos expertos como Henry Copeland sostienen que los periódicos deben abandonar la idea de que el monopolio de la información les pertenece, y han de conectarse cuanto antes a otras redes.

Para ello sugiere a los medios digitales algunas estrategias útiles:

${ }^{14}$ Díez Ferreira, Miguel A.: “Los confidenciales y la libertad de expresión”: Planet@Media.com, 11 de febrero de 2003.

15 "Nuestra función no es sólo producir el contenido, sino también guiar a nuestros lectores hacia otras fuentes de información”, manifiesta Simón Waldman, director de las ediciones digitales del diario británico.

16 "Los periodistas necesitan recibir una reacción, un parecer exterior sobre el modo en el que reproducen la actualidad. Yo, personalmente, trato de hacer mi 'caja negra' lo más transparente posible frente a los lectores de mi weblog, a quienes hago partícipes de mis dudas, mis preguntas e inquietudes sobre un tema actual. Soy consciente de que ellos, en colectivo, tienen muchos más conocimientos que yo sobre cualquier cuestión, y precisamente es la relación privilegiada que mantengo con estos lectores, la que aprovecho para enriquecer o reorientar mis artículos". 


\subsection{Estimular a los periodistas para que creen sus blogs}

Además de cubrir los acontecimientos del modo tradicional, los periodistas podrían utilizar páginas un poco más personales para transmitir observaciones y opiniones, o hacer comentarios sobre lo que han leído en la Red. Los lectores aprecian más el contacto con los individuos que con las instituciones. Algunos medios ya han dado ese paso. En el sitio de The New York Times, Paul Krugman, experto económico y colaborador del diario, dispone ya de un weblog, igual que los periodistas de la redacción internacional de $A B C$, que también tienen un dispositivo semejante en la página web de la cadena. En España, tenemos el caso del periódico El Mundo (www.elmundo.es) que cuenta con un blog, Retiario ${ }^{17}$, que es uno de los principales generadores de noticias de El Diario del Navegante, la sección de Internet y tecnología del diario. Otros medios españoles están potenciando esta estrategia entre sus periodistas como es el caso de Expansión con el blog de su periodista estrella, José Apezarena.

\section{2. $\quad$ Vincular su página a diversos weblogs}

"Muchos editores no saben que los weblogs pueden ser fuentes alternativas de información en la Red", dice Henry Copeland. "Al ignorar estas fuentes, el editor olvida su papel de nexo comunitario, pasa por alto audiencias que, por su número, deberían ser tenidas en consideración y se priva de nuevos objetivos comerciales".

\subsection{Proponer una plataforma de creación de weblogs para los lectores}

Estrategia muy adecuada para los editores locales, que disfrutan ya de una comunidad de lectores asentada que sólo espera a ser conectada a la Red. Cuanto más "blogueen" (una forma de definir el acto de acceder a los blogs) los lectores y más se conecten entre sí, mayor es el peso de un periódico en tanto que nexo comunitario. Es matemático: un diario con diez lectores crea diez relaciones, diez lectores crean cincuenta. La edición en red aumenta de forma exponencial.

\subsection{Animar a los blogs a vincularse a su contenido}

Los editores que se prohíben a sí mismos el "deep linking” (vínculo directo a la página en la que se sitúa el artículo) terminan consiguiendo que los bloggers retomen los contenidos sin hacer referencia a su portal, ni referirse a su marca.

\footnotetext{
${ }^{17}$ elmundo.es se inició en el mundo de los blogs con Retiario, el primero en existir entre los grandes diarios españoles online. Retiario se ha convertido en uno de los principales generadores de noticias de El Diario del Navegante, la sección de Internet y tecnología de elmundo.es.
} 


\section{Blogs que destruyen carreras periodísticas: participación ciudadana}

Según un artículo publicado en The New York Times en febrero de 2005, algunos medios de comunicación tradicionales de EE.UU. empezaron a alarmarse al ver carreras profesionales destrozadas por lo que ellos contemplan como el creciente poder del diálogo incontrolado y no editado: los blogs.

Esta preocupación surge como consecuencia de la dimisión de Eason Jordan, ex ejecutivo de la CNN, quien intervino en el Foro Económico Mundial de Davos, en Suiza, a finales de enero y que dijo según testigos, que creía que el ejército de EE.UU. había disparado contra periodistas en Irak y matado a 12 de ellos. La exactitud de sus palabras no estaba del todo clara, y el Foro, que grabó en vídeo la conferencia, no ha publicado la cinta. El 11 de febrero de 2005, Jordan dimitió de su puesto de ejecutivo de la CNN, manifestando que "nunca quise dar a entender que las fuerzas estadounidenses hubieran actuado con mala intención cuando mataron accidentalmente a periodistas".

Varias personas del círculo de Jordan se han esforzado en indicar que la dimisión del ejecutivo no se debe solo a las críticas que la cadena CNN ha estado recibiendo en la Red. Pero lo cierto es que días después de su declaración, aparecieron muchos blogs saturados con mensajes de indignación que decían que se estaba calumniando a la tropas americanas. Analistas e investigadores del caso, como Jeff Jarvis, jefe de la división de Internet de Advance Publications, publica en su blog buzzmachine.com la siguiente reflexión: "Quisiera que nuestro objetivo no fuera cortar cabezas, sino desenterrar la verdad".

Algunos directivos de medios y periodistas profesionales han lanzado una voz de alarma considerando que se vislumbra una especie de "tontos de baba que componen las turbas de linchamiento" en clara referencia a lo sucedido con el caso Jordan.

Y es que la audiencia en Internet ha dejado de ser pasiva. Los lectores han pasado a la acción de opinar en el mundo virtual. Y al igual como sucede en el mundo tradicional, la audiencia manda, solo que aquí opina y publica lo opinado para conocimiento de todo el mundo, a diferencia de lo que ocurre en el mundo tradicional, en donde una opinión o queja se hace a través de las cartas al director o a través del ombusdman, si el medio lo tiene. Todo esto ha motivado que algunos veteranos periodistas en EE.UU. se pregunten: “iHemos entrado acaso en una era en la que nuestras vidas pueden ser destruidas por una manada de lobos armados con sus teclados sin la menor supervisión y sin obligación de rendir cuentas?"'.

La participación de los ciudadanos a través de los blogs conforma el perfil de la nueva audiencia de Internet. Esto implica que los medios, y los profesionales en ellos incluidos, tienen que rendir cuentas más que nunca a los ciudadanos quienes no perdonan una labor de investigación periodística descuidada y comentarios incendiarios sin fundamento, especialmente si éstos tratan temas de alcance nacional.

Según expertos analistas estadounidenses, los bloggers de tinte político conservador vieron las afirmaciones atribuidas a Jordan como una prueba de la tendencia liberal de los medios de comunicación 
americanos. Basan su afirmación, de acuerdo con las afirmaciones de Rebecca MacKinnon, quien trabajó para Jordan como productora y jefe de corresponsales de la CNN. Ella puso sobre aviso a Jordan informándole de que los blogs de tendencia conservadora hacían circular sus comentarios, que habían sido "colgados" por primera vez en el blog de Ronny Abovitz, un empresario de Florida que había asistido al Foro. MacKinnon dijo a Jordan que los mismos que habían hecho caer a Rather iban a por él (Jordan), refiriéndose al caso del periodista y presentador de noticias, Dan Rather, quien anunció que dejaba la cadena en marzo pasado, como consecuencia de la acusación que le hicieron los bloggers de información incorrecta durante la campaña presidencial.

Abovitz, que fue quien lo empezó todo, ha manifestado que tenía la esperanza que los bloggers conservadores hubiesen sido capaces de tener unos objetivos más nobles y no el de destruir la carrera de algunos. Afirma que "si se va hacer este periodismo de código abierto, debería tener un propósito más elevado".

Los blogger conservadores han demostrado que pueden hacer rodar cabezas, actuando como una muchedumbre furiosa, y una muchedumbre furiosa que utiliza alta tecnología no es nada positivo.

\section{Los weblogs en otros entornos de la comunicación}

La importancia de los weblogs como medios complementarios a las cabeceras tradicionales se refleja en casos como el de Harry Knowles, que ha conseguido llegar a ser un crítico de cine influyente en el mundo de Hollywood gracias a la información que publica en su página web Ain't it cool news. Ésta es citada por numerosas publicaciones desde la revista Variety hasta The New York Times. La información cinematográfica que publica Knowles trata sobre decisiones estratégicas de los estudios, alteraciones de montaje, cambios en los guiones o test de estrenos a lo que hay que unir la cantidad de cotilleos que conoce, en resumen, todo tipo de información secreta que los productores no quieren que se conozca. La mayoría de sus informadores trabajan en los estudios como ayudantes o maquilladores y tienen acceso a guiones y datos más o menos confidenciales que son publicados sin que los responsables de la producción puedan encontrar la fuente. Ain't it cool news empezó a ser conocido por desvelar datos secretos relacionados con el rodaje de la última parte de "La Guerra de las Galaxias". Entre ellos el nombre del actor protagonista ${ }^{18}$.

Uno de los blogs más famosos es, sin duda, Slashdot, fundado en septiembre de 1997 por Rob Malda y Jeff Bates. Slashdot es el referente de toda una comunidad de expertos en informática y nuevas tecnologías que, por lo general, no suelen sentirse cómodos en la sociedad real. Este grupo de hackers, nerds o geeks, como se les conoce en Estados Unidos, usa el web para relacionarse entre iguales y

\footnotetext{
${ }^{18}$ Olivares, Paco: “¿Los nuevos media implican una nueva ética?”, en espanol-geocities.com.
} 
compartir información ${ }^{19}$. Cada día reciben más de 200 artículos de los que sólo un 5 por ciento serán publicados.

\subsection{El papel de los weblogs en las estrategias de comunicación}

Si un asesor de una empresa de comunicación española comentara: "Existe un nuevo medio que puede crear opinión sobre su empresa, que puede dar a conocer información interna sobre ustedes, que no es fácil de controlar y que empiezan ya a ser comentados por algunos medios escritos en España", evidentemente muchos empresarios se quedarían perplejos. Aunque de momento podemos tranquilizarnos. Estos nuevos medios -los blogs- aún no están muy extendidos en España, pero sí es cierto que algunos de ellos ya son fuente de información habitual para varios medios escritos en nuestro país.

Estamos asistiendo a un auge de blogs gestionados por miembros de la comunidad académica, especialistas en sectores, líderes de opinión, etc. Por tanto, nuestra recomendación es que las empresas deben informarse sobre el funcionamiento de estas nuevas herramientas de información y que se determine el papel que puedan tener en su futura estrategia de comunicación y en sus relaciones con los medios.

En Estados Unidos, varias empresas han visto cómo en periodos de despidos masivos o en campañas en medios sobre supuestos abusos en las condiciones laborales de sus trabajadores o contratas, diversos blogs estaban aportando información muy detallada sobre sus políticas internas, procesos, información sobre decisiones de directivos, etc. Estas informaciones publicadas en diferentes weblogs se convierten en fuente de información, o al menos en fuente de investigación, para muchos medios de comunicación, sindicatos y terceras partes involucradas en cualquier conflicto.

En el ámbito político, las elecciones presidenciales primarias de Estados Unidos nos están dando también muchas claves sobre el potencial de los weblogs en las campañas políticas. Todos los candidatos del Partido Demócrata están llevando a cabo una intensa campaña de comunicación a través de weblogs para difundir sus mensajes, recaudar fondos, movilizar voluntarios para sus campañas y hasta para intoxicar el mensaje del contrario.

Cuando los medios de comunicación tradicionales entraron en Internet, poca gente prestó atención a aquellos ociosos que escribían diarios "on line" y discutían en foros de debate. Y es que no se pensó que esas páginas personales temáticas se iban a situar como fuentes de la opinión pública, ofreciendo un punto de vista y opinión que en muchas ocasiones en nada se parece a lo publicado en los medios tradicionales, donde existen mayores limitaciones de expresión.

\footnotetext{
${ }^{19}$ A finales de junio de 1999 Andover.net compró el web de Slashdot por 10 millones de dólares.
} 
A medida que estas reflexiones se van extendiendo entre los asiduos a los weblogs, la información aportada está llegando en muchos casos a los medios tradicionales y entonces su gestión por parte de los afectados se convierte en una tarea muy ardua.

Lo que está claro es que los weblogs han permitido democratizar el acceso a la información, consiguiendo acceder a un sistema de comunicación en el que las personas pueden expresarse libremente sin ningún tipo de censura, lo que lo convierte en el medio adicional idóneo para obtener información y compartir opiniones.

La mayoría de los gabinetes de prensa y comunicación tienen sistemas de seguimiento de medios para detectar cobertura, noticias de interés, alertas, etc. En la Red existen más de cuatro millones de blogs en el mundo. No sería mala idea llevar a cabo una pequeña auditoría en la Red para investigar sobre la existencia de bitácoras en su sector, actividad empresarial, etc.

Un buen comienzo es www.bitacoras.net y www.blogdir.com; aquí se encuentra la comunidad más grande de weblogs en español; también pistas para hacer un weblog, con un buen ordenamiento por categorías. Y gracias a los "tracback" (sistema para crear intercambios de información por medio de enlaces; algo, por otro lado, impensable en la prensa digital tradicional) se facilita el paso de un weblog a otro dentro de una misma temática.

\section{Conclusiones}

El mundo de los blogs marcan la segunda generación de páginas en Internet, con la particularidad de que las herramientas que se utilizan son fáciles de usar por cualquier persona que posea unos mínimos conocimientos informáticos. Si anteriormente fueron los "gurus" de la información los "iluminados" en vaticinar con aciertos o desaciertos el desarrollo de la Red en el ámbito periodístico, hoy son los empresarios los que dan la voz de alarma. Así lo ve el magnate de la comunicación Rupert Murdoch, presidente de News Corporation, en un discurso ${ }^{20}$, en abril de 2005, a los editores de la Sociedad Norteamericana de Editores de Diarios.

Vemos pues, que la Red se avizora como segunda oportunidad en diferentes aspectos de la comunicación con el advenimiento y posicionamiento de las bitácoras en el periodismo y los medios.

\subsection{Participación ciudadana o la opinión de la audiencia}

A pesar de la influencia que puedan tener ciertos weblogs, el debate con los medios tradicionales continúa abierto hasta tal punto que han llegado a producirse enfrentamientos directos entre las partes. Así

\footnotetext{
${ }^{20}$ Murdoch sostuvo que, "como periodistas, estamos situados en una posición privilegiada para transmitir noticias a la sociedad. Poseemos la experiencia, los recursos, la plataforma y herramientas para diferenciarnos en un mundo donde la información se ha convertido en un producto de consumo. Y, lo más importante, poseemos un nuevo aliado para hacerlo y poder, así, conectarnos con el nuevo perfil del consumidor: Internet".
} 
tenemos el caso de la cadena televisiva CBS, que se ha visto obligada, ante la denuncia de algunos weblogs, a pedir perdón por la utilización de una falsificación en un programa de máxima audiencia. Los papeles falsificados que la CBS no comprobó pretendían demostrar que George W. Bush faltó a sus obligaciones haciendo el servicio militar en la Guardia Nacional Aérea de Texas en los años setenta. Igualmente se denunció a través de weblogs el asunto de los Veteranos de Lanchas Rápidas por la Verdad y su campaña acusando al candidato demócrata John Kerry de falsificar sus registros en Vietnam.

En el caso de España, diarios como elpais.es se han visto obligados a pedir disculpas por una campaña publicitaria para la captación de suscriptores que utilizaba imágenes del atentado contra las Torres Gemelas de Nueva York antes y después del 11-S, y que algunos encontraron ofensivas ${ }^{21}$. Las protestas de los blogs han forzado una reacción del diario pidiendo perdón en portada ${ }^{22}$.

Este tipo de situaciones son las que llevan a cuestionarse la amenaza que puedan suponer los weblogs a la posición de la prensa tradicional como cuarto poder. No olvidemos los intereses económicos e ideológicos que mueven a los grupos de comunicación, y que evidentemente marcan los principios configuradores del medio, pues muchas veces el weblog es una reacción de los periodistas frente al sistema de valores que impera en los negocios informativos.

\subsection{Conversión de los blogs en sitios periodísticos}

Varios son los casos en los que un weblog o bitácora se convierte en un referente periodístico. Más aún, varios son los medios de comunicación tradicionales que en sus sitios web no dudan en promover los blogs de sus periodistas o en el mejor de los casos, hacerse de una bitácora que ya tiene cierta "fama" en la Red. Uno de estos casos, en los que se mezcla la participación ciudadana, es el caso de un iraquí de 29 años cuya identidad nadie conoce pero que se hizo famoso internacionalmente por su seudónimo, (salam en árabe significa paz al igual que pax en latín). Salam empezó a ser conocido a raíz de que la agencia británica de noticias Reuters citase su weblog, ¿Where is Raed? en un teletipo. Antes de su aparición en los grandes medios, el autor sólo colgaba en la red sus pensamientos y mensajes dirigidos a su amigo Raed, que vivía en Jordania y que nunca contestaba a sus correos. Hoy, sus crónicas, que mezclan su visión personal de la vida con sus ácidos comentarios sobre la situación de Bagdad durante la guerra, son publicadas en el libro "Salam Pax: el internauta de Bagdad" (Arena Abierta). En un tono irónico, moderno, divertido y profundamente sincero, Salam recolecta las experiencias diarias de un iraquí antes, durante y después de la invasión de su país por EEUU y Reino Unido. A pesar del relativo anonimato que permite la Red, Salam sintió de cerca el miedo. Sobre todo cuando su bitácora empezó

${ }^{21}$ La campaña se realizó a través del correo electrónico, entre el 13 de septiembre y el 15 de septiembre. elpais.es, 16 de septiembre de 2004.

${ }^{22}$ Cervera, José: “El fin del cuarto poder”: 20 minutos, 24 de septiembre de 2004, p. 21. 
a ser mencionada por los grandes medios de comunicación. Diarios, televisiones y radios citaban su página como una referencia, un halo fresco dentro del magma informativo que generaba la guerra en Irak, que padecía el riguroso control de ambos bandos.

En la actualidad se puede acceder al blog de Salam Pax, quien ha conseguido que el diario inglés The Guardian le publique una crónica quincenal. La paradoja estriba en que su testimonio, escrito en la Red y diseñado especialmente para ella, ha llegado al papel.

\subsection{Como enfoque de negocios}

Los medios de comunicación empiezan a desarrollar estrategias que hagan más rentable la materia prima que producen: la información (Flores y Aguado) ${ }^{23}$. News Corp., The New York Times Company, Time Warner... tras las apuestas apresuradas -y en muchos casos fallidas- por hacerse un hueco en la Red en plena burbuja de los 90, los principales grupos de medios vuelven a tomar posiciones en Internet. En el último año se han sucedido una serie de compras millonarias. El magnate Rupert Murdoch, por ejemplo, es de los más entusiastas. Sólo en los últimos meses, su grupo, News Corp., ha invertido cerca de 1.300 millones de dólares -unos 1.080 millones de euros- en la compra de sitios como MySpace.com -orientado al público adolescente- o el portal de videojuegos GameSpy.com.

Y no es el único. The New York Times Company, editora de The New York Times, pagó más de 300 millones de euros en febrero por About.com, un sitio que agrupa hasta 500 blogs con consejos prácticos para la vida cotidiana y que atrae cada mes a más de 22 millones de personas. Otra "grande", Viacom (dueña de CBS, MTV, Paramount Pictures, Blockbuster, Comedy Central, y la editorial Simon \& Schuster) ha optado por invertir más de 46 millones de dólares en la compra del 60 por ciento del portal de deportes SportsLine.com que no poseía. Incluso The Wall Street Journal, uno de los pocos medios que ha conseguido cobrar por su contenido en la web, decidió en enero ampliar su presencia con la adquisición del portal de finanzas de acceso gratuito Marketwatch.com, por el que pagó 528 millones de dólares.

\subsection{Como fuente informativa}

Dentro de nuestra realidad, la incorporación de blogs como fuente informativa aún requiere de una mayor profundización. No obstante, algunos expertos no dudan en afirmar que se les valora como un formato nuevo que puede enriquecer la labor periodística, permitiendo un periodismo más cercano y

${ }^{23}$ Los modelos de negocio que empiezan a desarrollar las empresas de medios es una cuestión prioritaria en el actual panorama del sistema mediático... (Flores y Aguado: Modelos de Negocio en el Ciberperiodismo). 
mayor interactividad con los lectores. Otro aspecto es la credibilidad que aún mantienen los medios de comunicación frente a este nuevo modo de entregar información ${ }^{24}$.

\subsection{Los aspectos éticos}

Según Gerardo Albarran, periodista-editor de Sala de Prensa (Islas, Albarran y otros, 2002: 380), en la globalización de la irracionalidad, lo que sorprende no es que gente desprevenida, ajena a cualquier abstracción de los fenómenos comunicacionales, reproduzcan mensajes fuera de todo crédito, sino que lo verdaderamente alarmante es que los periodistas (y los académicos que enseñan periodismo) rindan todos los principios deontológicos por las mismas razones. De todo ello se deduce que para el periodismo, el anonimato y libertad que imperan en el formato blog lo convierte en una herramienta peligrosa en el momento de ser citado. Por tanto, el mayor desafío está justamente en la credibilidad. Evidentemente, esto se circunscribe al periodismo en general, que puede, eventualmente, reproducir versiones no comprobadas de hechos o acusaciones infundadas o no contrastadas.

El alcance global de los blogs y su información aún no tiene reglamentos que ajusten los contenidos a un marco ético y legal, distanciándolos así de convertirse en fuentes reales de información.

En un primer esfuerzo por instituir ciertas reglas morales, CyberJournalists.net ha creado un estatuto que modifica al Código Ético para la Sociedad de Periodismo Profesional, que actualmente rige las prácticas profesionales del periodismo norteamericano, ya que, según lo establecido por este gremio, "la integridad es cimiento de la credibilidad".

Lo que sí permanece incólume es la confianza que los medios de comunicación tradicionales le transfieren al usuario, a diferencia de los weblogs por Internet.

En España nos basamos en la Ley de Servicios de Sociedad de la Información y Comercio Electrónico, conocida como Ley Internet, pero está enfocada a las páginas de información periodísticas y no a diarios personales como ocurre con el tipo de publicación que se da en los blogs.

\subsection{Periodismo blog, ¿un nuevo periodismo?}

El reciente ataque terrorista en Londres se amplificó a nivel mundial en tiempo récord, pero esta vez la pauta la dieron los blogs o bitácoras personales por Internet. Las imágenes y textos de más de mil trescientos de estos diarios de vida transformaron al ciudadano inglés en reportero, editor y columnista,

\footnotetext{
${ }^{24}$ Victoria Carvallo, periodista del diario chileno La Tercera, dice: "En La Tercera online no los utilizamos como medio informativo, porque la fuente no es creíble al ser desconocida. Como política editorial sólo recurrimos a blogs de medios consolidados, cuyo soporte es su principal carta credencial. El periódico El Mundo de España, por ejemplo, posee un blog de su corresponsal en Irak, transformándolo en una fuente internacional válida porque está respaldado por la firma de su periodista".
} 
potenciando así la interacción entre el público y los medios informativos. Se constituyeron en los mejores corresponsales de medios de consolidada trayectoria como la $B B C$ y The Guardian, aunque la gran cuestión es si los blogs son o no verdadero periodismo.

Orville Schell, decano de la Facultad de Comunicación de la Universidad de California en Berkeley, en una entrevista con Newsweek, sostuvo que "el imperio romano que representaban los medios de comunicación ha comenzado a desmoronarse. Estamos entrando a una era feudal en donde habrá muchos centros de poder e influencia”.

Esta idea se confirma al comprobar que los blogs han comenzado a complementar las versiones online de prestigiosos medios como Le Monde en Francia, Kleine Zeitung en Austria o el Wall Street Journal en Estados Unidos.

Ante este panorama, estamos quizás asistiendo al nacimiento de un nuevo periodismo, Periodismo blog, cuya característica principal sea la participación masiva de la audiencia, que deja su lado pasivo para convertirse en una audiencia preactiva.

En España son varios los medios tradicionales de información que recurren a enterarse de alguna noticia de importancia en páginas de conocidos bloggers, quienes publican en sus bitácoras hechos como las recientes catástrofes naturales (como el terremoto de Pakistán o las secuelas del huracán Katrina, en EE.UU.) o sobre algún conflicto bélico (Guerra de Irak) o sobre algún hecho político-social (recientes sucesos de enfrentamientos en Francia).

\subsection{Expansión imparable}

To blog or not to blog es el dilema del nuevo periodismo independiente y que algunos le atribuyen una forma verbal (to blog). Cada quién actúa por cuenta y riesgo propios. El lector no está atado a los editorialistas de una publicación determinada (que lee como suscriptor o por afinidad ideológica), y el periodista disfruta de absoluta libertad para escribir y publicar lo que quiera. No hay línea editorial ni límite de espacio (salvo los impuestos por el buen gusto y la razón), lo que permite al blogger escribir breves ensayos o comentarios sobre temas de política, cocina, literatura, fotografía y "de todo". Francis Pisani, periodista que escribe diariamente en Le Monde digital (http://pisani.blog.lemonde.fr/pisani/) y el suplemento Ciberpais (El País) sobre informática y novedades tecnológicas, es un convertido blogger. Dice que los blogs le permiten "escapar del formalismo editorial sin perder el rigor de la profesión”.

El fenómeno de los weblogs sólo acaba de comenzar y ya ha generado apuestas millonarias. Dave Winer, director de Userland.com y Martin Nisenholtz, director de The New York Times digital, han realizado una curiosa apuesta. Dave se apuesta 1.000 dólares a que en el 2007 las palabras o frases referidas a las cinco noticias más importantes estarán en weblogs antes que en el sitio web de The New York Times. Nisenholtz, por su parte, se apuesta otros 1.000 dólares a lo contrario. Y esto sólo es el comienzo. 


\section{Referencias bibliográficas}

- Bowman, S., Willis, C. y The Media Center at The American Press Institute (2003): Nosotros, el medio. Colombia: Casa editorial El Tiempo (trad. Guillermo Franco).

- Castells, M. (2001): La Galaxia Internet. Barcelona: Plaza \& Janés.

- Cervera, J. (2004): “El fin del cuarto poder”, 20 minutos, p. 21.

- Flores, J. y Arruti, A. (2001): Ciberperiodismo, nuevos enfoques, conceptos y profesiones emergentes en el mundo infodigital. Madrid: Ediciones 2010.

- Díaz Noci, J. (2004): “Medios digitales españoles en Internet”, Telos n. ${ }^{\circ}$ 59, pp. 56 y 57.

- Flores, J. y Aguado, G. (2005): Modelos de negocio en el Ciberperiodismo. Madrid: Fragua editorial.

- Islas, O. et al. (2002): Explorando el ciberperiodismo iberoamericano. México: Editorial Continental.

- Timoteo Álvarez, J. (2005): Gestión del poder diluido. Madrid: Pearson Comunicación.

\section{Sitios Web de referencia}

- Díez Ferreira, M. A.: “Los confidenciales y la libertad de expresión”, www.geocities.com consultado el 11 de febrero de 2003.

- Manchon, E.: "Entrevista a José Cervera: Weblogs e Internet en España”, www.alzado.org consultado el 3 de septiembre de 2004.

• Manchon, E.: “¿Hacia dónde van los weblogs?”, www.alzado.org consultado el 20 de enero de 2004.

- Olivares, F.: “¿Los nuevos media implican una nueva ética?”, www.geocities.com

- "Microsoft lanza un servicio de weblogs en Japón", www.elmundo.es consultado el 4 de agosto de 2004.

- "Reflexiones sobre el mundo del weblog", www.paraperiodistas.com consultado el 15 de septiembre de 2004. 